\title{
Motivação e desmotivação: desafio para as professoras do Ensino Fundamental
}

\section{Encouragement and discouragement: a challenge to High Schooll teachers}

\author{
Luciane Knüppe*
}

\begin{abstract}
RESUMO
No processo ensino aprendizagem acredita-se que a motivação deve estar presente em todos os momentos. Cabe ao professor facilitar a construção do processo de formação, influenciando o aluno no desenvolvimento da motivação da aprendizagem. O relato desta pesquisa que teve como objetivo investigar como as professoras motivam seus alunos e que recursos utilizam para isso, constatou que as educadoras do Ensino Fundamental $\left(1^{\mathrm{a}}\right.$ a $4^{\mathrm{a}}$ série) precisam motivar seus alunos para o ensino, e para isso necessitam estar motivadas; realizar atividades criativas e envolventes.

Palavras-chave: motivação; metas; objetivo; ensino; aprendizagem.
\end{abstract}

\begin{abstract}
In this process of teaching instruction trade school we believe that the motivation can be present all the moments. The teacher has to facilitate the construction of this formation process, in order to influence the students on his develop and in this motivation for the trade school. The mention of this search that had like objective to investigate how the teachers motivate tbeiro students and the petition can be use for this we proved that the teachers of elementary school ( 1 to 4 grades) need to motivate their students for the teaching instruction and for this it's necessary the students to be motivated too for realize creative and involve activities.

Key-words: motivation; goals; objective; education; learning.

* Mestre em Educação pela Pontifícia Universidade Católica do Rio Grande do Sul (PU-
\end{abstract} CRS) 
KNÜPPE, L. Motivação e desmotivação: desafio para as professoras...

\section{Introdução}

A criança de hoje vive em um mundo repleto de tecnologias e brinquedos que encantam e fascinam a todos. Os atrativos oferecidos pela mídia despertam interesses que estão além do simples fato de freqüentarem uma escola. No entanto, essa, muitas vezes, não oferece os mesmos atrativos, o que na maioria dos casos gera certos desinteresses e falta de motivação pelos estudos, pois para uma criança, brincar é muito mais interessante do que estudar. Embora as pessoas saibam da importância da educação para o desenvolvimento do ser humano, fazer com que os meninos e as meninas compreendam isso é um grande desafio.

Pesquisas mostram que as crianças estão chegando às escolas cada vez mais desmotivadas com os estudos, o que gera a repetência e muitas vezes a evasão escolar. Segundo Zenti (2000), são muitos os problemas causados pela desmotivação, no entanto acredita que não existe uma receita mágica para fazer as aulas serem o foco de atenção das crianças. Porém, afirma que o professor com sensibilidade e energia talvez consiga enfrentar o desafio.

Para Zenti (2000), os especialistas no assunto afirmam que os professores devem mostrar aos seus alunos que estudar pode ser divertido. Porém, a maior dificuldade está em competir com os atrativos tecnológicos e os brinquedos que encantam as crianças, e que na escola não existem.

De acordo com Torre (1999), na maioria dos encontros de professores, a queixa presente é com relação ao desinteresse dos alunos em querer aprender. No entanto acreditam que "esse fato afeta diretamente professores e alunos em função das áreas de estudo, dos níveis do sistema educacional e das características socioculturais de quem aprende, entre outras variáveis” (p. 07).

Frente a essas premissas e, com a intenção de investigar a motivação nas salas de aulas de crianças do ensino fundamental $\left(1^{\mathrm{a}}\right.$ a $4^{\mathrm{a}}$ série), aponto como problema da pesquisa:

Como as professoras de ensino fundamental $\left(1^{a} a 4^{a}\right.$ série) motivam seus alunos para os estudos em sala de aula?

O objetivo principal desta pesquisa foi de investigar como as professoras motivam seus alunos e que recursos utilizam para isso.

Segundo Torre (1999), “a motivação escolar é algo complexo, processual e contextual, mas alguma coisa se pode fazer para que os alunos recuperem ou mantenham seu interesse em aprender” (p. 09). 


\section{Metodologia}

O método empregado nesta pesquisa foi o qualitativo porque "a abordagem qualitativa parte do princípio de que há uma relação dinâmica entre o mundo real e o sujeito, uma interdependência viva entre o sujeito e o objeto, um vínculo indissociável entre o mundo objetivo e a subjetividade do sujeito” (CHizzotті, 1991, p. 79).

O processo de investigação que norteou a temática da pesquisa situou-se na metodologia do estudo de caso. Segundo André (1998), utiliza-se o estudo de caso quando se busca descobrir novos conceitos sobre um determinado fenômeno.

Os dados da pesquisa foram coletados por meio de entrevistas individuais com dezesseis professoras, sendo oito de escolas públicas e oito de escolas privadas. O número de participantes não foi definido a priori, mas de acordo com o critério do "ponto de saturação de dados" (BOKDAN; BIKLEN, 1994). Essas entrevistas foram gravadas e transcritas na íntegra. As professoras entrevistadas foram escolhidas por indicação do serviço de supervisão das escolas, as quais foram indicadas por serem consideradas profissionais motivadas com o trabalho e com a entidade em que pertencem. As entrevistas ocorreram nas escolas em horário de trabalho. As escolas foram escolhidas aleatoriamente.

Os dados foram estudados utilizando análise de conteúdo segundo Bardin (1991). A análise de conteúdo é um conjunto de técnicas de análise das comunicações. "Não se trata de um instrumento, mas de um leque de apetrechos; ou com maior rigor, trata-se de um único instrumento, mas marcado por uma grande disparidade de formas e adaptável a um campo de aplicação muito vasto: as comunicações” (BARDIN, 1991, p. 31).

“A análise de conteúdo é uma técnica de investigação que tem por finalidade a descrição objetiva, sistemática e quantitativa do conteúdo manifesto da comunicação” (BERELSON, apud BARDIN, 1991, p. 19). Através da análise de conteúdos será possível reinterpretar as entrevistas e atingir uma compreensão de seus significados num nível que vai além de uma leitura comum. (MORAEs, 1999). Segundo Moraes (1999), essa metodologia de pesquisa faz parte de uma busca teórica e prática, com um significado especial no campo das investigações sociais. 
KNÜPPE, L. Motivação e desmotivação: desafio para as professoras...

\section{Referencial teórico}

A motivação é entendida, segundo Huertas (2001), como um processo psicológico, ou seja, ela é proporcionada por meio dos componentes afetivos e emocionais. No entanto, as pessoas possuem diferentes tipos de motivação para um determinado assunto.

As pessoas criam metas em suas vidas, sua carreira profissional ou até mesmo em viagens, e são essas metas que as motivam a continuar seus objetivos e propósitos. Para Huertas (2001), a motivação é a energia psíquica do ser humano.

De acordo com os estudos de Fita (1999) “a motivação é um conjunto de variáveis que ativam a conduta e a orientam em determinado sentido para poder alcançar um objetivo” (p. 77). Assim, a motivação consiste em determinadas ações que levam as pessoas a alcançar seus objetivos.

Segundo Weiner (1979), as causas às quais os alunos atribuem seus êxitos ou fracassos podem ser classificadas seguindo diferentes critérios: causas internas ou externas, segundo as causas se encontrem no interior do sujeito ou fora dele; estáveis ou instáveis, segundo respondam a algo permanente ou mutável e, por último, controláveis ou incontroláveis, segundo seja possível ou não intervir nelas (FITA, 1999, p. 81).

Huertas (2001), salienta que existem dois tipos de motivação: motivação intrínseca e a motivação extrínseca.

A motivação intrínseca está relacionada ao interesse da própria atividade, que tem um fim em si mesma e não como um meio para outras metas. Pode ser considerada como um sistema motivacional independente dos demais, que suporta um tipo concreto de antecipação de metas e um conjunto de crenças e atitudes. Para Huertas (2001), quando uma ação se encontra regulada intrinsecamente, esta se fundamenta principalmente em três características: autodeterminação; competência e satisfação em fazer algo próprio e familiar. Segundo Fita (1999), "a própria matéria de estudo desperta no indivíduo uma atração que o impulsiona a se aprofundar nela e a vencer os obstáculos que possam ir se apresentando ao longo do processo de aprendizagem” (p. 78).

A motivação extrínseca está relacionada às rotinas que vamos aprendendo ao longo de nossas vidas. Segundo Huertas (2001), quando a finalidade da 
ação, a meta, e o propósito têm haver com uma contingência externa, com uma promessa de um benefício tangível e exterior, se fala de motivação extrínseca. Pode-se dizer que a motivação extrínseca é aquela que vem de fora, e está associada à matéria, à remuneração, ao ter.

No processo ensino-aprendizagem, a motivação deve estar presente em todos os momentos. Quanto a isso, Fita (1999) explica que muitas vezes dizemos que para o aluno ter motivação em aula é importante ter um bom professor. Ouve-se dizer também, que um bom professor é aquele que sabe motivar seu aluno. De acordo com esse posicionamento, Huertas (2001) salienta que toda motivação deve estar relacionada a metas e objetivos, portanto, um bom professor possui metas de ensino, o que tornará o aluno motivado a aprender.

Huertas (2001) afirma que as metas são desencadeadoras da conduta motivada, formam parte do núcleo imprescindível para considerar uma ação como motivada ou não. Portanto, sem desejo e metas, não há motivação. No entanto, para haver aprendizagem é preciso haver a motivação.

O papel do professor, segundo Huertas (2001), não é o de influenciar o aluno quanto às suas habilidades, conhecimentos e atitudes, mas o de facilitar a construção por parte deles do processo de formação. Frente a essa idéia, o professor influenciará o aluno no desenvolvimento da motivação da aprendizagem. Para o autor, quanto mais consciente for o professor com relação a motivação, melhor será a aprendizagem de seu aluno.

"La motivación en la escuela depende más del tipo de metas que com regularidad se plantee un alumno que del tipo de atribuciones que haga" (HUERTAS, 2001, p. 256).

\section{Análise}

A motivação dos alunos pelos estudos em sala de aula, é um assunto preocupante, pois, segundo as professoras entrevistadas, as crianças estão chegando cada vez mais desmotivadas. Muitas relataram que a escola está perdendo espaço para os avançados brinquedos e video-games, que encantam e acabam interferindo no aprendizado. "A escola não é mais um lugar legal. As crianças preferem ficar em casa assistindo um vídeo ou brincando na praça, porque aqui eles ficam copiando do quadro e sentados a tarde toda. Que graça tem?”.

Os relatos mostraram que muitas professoras estão desmotivadas com 
KNÜPPE, L. Motivação e desmotivação: desafio para as professoras...

o método de ensino e com a receptividade de seus alunos. Alegam que estar na escola hoje, para uma criança sadia e cheia de energia, é algo cansativo e desgastante. Quanto a isso, Pozo (2002) explica que "na aprendizagem, é preciso procurar sempre um motivo" (p. 138), e o que essas professoras relatam é que seus alunos não o estão encontrando.

A desmotivação gera graves conseqüências como a repetência e a evasão escolar. Nas escolas públicas, muitas crianças, por repetirem várias vezes a mesma série, optam por sair da escola e ingressar no mundo do trabalho, o qual traz um retorno financeiro, causando assim a evasão nas escolas. Porém, segundo as professoras entrevistadas, nas escolas particulares a repetência está relacionada ao desinteresse dos alunos, o que Pozo (2002) afirma estar muito relacionado a motivação, ou a falta de. Explica que, "normalmente, não é que não estejam motivados, que não se movam em absoluto, mas sim que se movem para coisas diferentes e em direções diferentes das que pretendem seus professores" (p. 139). Como ilustrou uma entrevistada: "A gente fica ali na frente se matando pra ensinar alguma coisa, e eles parecem que não estão nem aí. Estão preocupados com outros assuntos".

A pesquisa mostrou que as professoras das primeiras séries do Ensino Fundamental estão preocupadas com a desmotivação dos alunos para com os estudos, no entanto, para sanar essa atitude de desconforto por parte das crianças, as educadoras estão criando aulas mais encantadoras e que partem do interesse e da realidade de seus alunos. A utilização de recursos como jogos confeccionados pela professora e avental para contar histórias estavam muito presentes no dia a dia.

A motivação não é um problema apenas dos alunos, mas dos professores também. Como ilustrou a fala de uma entrevistada: "Eu entendo meus alunos. Às vezes eu também vou dar aula sem vontade de nada". As professoras acreditam que para os alunos estarem motivados com a aprendizagem, é preciso que elas estejam motivadas. De acordo com Jesus e Santos (2004), a rotina e a inibição provocam a desmotivação.

As professoras relataram que nem sempre estão motivadas para o trabalho. Muitas vezes vão trabalhar cansadas. Elas acreditam que essa atitude, de alguma maneira, é percebida pelos alunos, o que faz com que se comportem desmotivados. "Noto que quando estou empolgada, meus alunos também estão. E quando estou baixo astral, eles também ficam. Parecem que captam o humor da gente". Segundo Huertas (2001), pouco a pouco vamos aperfeiçoando as habilidades e os esquemas motivacionais, estabelecendo mais metas, as quais serão mais compreensivas.

Essa desmotivação pelo trabalho, está relacionado, segundo Jesus e Santos (2004), com as condições de trabalho oferecidas ao profissional da 
educação, que muitas vezes não recebem um salário de acordo, trabalham com um grande número de crianças e com poucos recursos tecnológicos. Como relatou uma entrevistada: "A gente traz problemas de casa sim. Mas o nosso maior problema é quanto ao número de alunos. A gente dá aula pra quase quarenta crianças em uma primeira série. E a qualidade do nosso trabalho onde fica?". Essa constatação destacou-se nas entrevistas das professoras de escolas públicas. De acordo com a pesquisa realizada por Moreira (1997), constata-se que a motivação é um fenômeno complexo e se constitui um elemento essencial à própria razão de ser professor.

A análise dos dados mostrou que a falta de motivação também está muito relacionada ao grande número de alunos nas salas de aulas. As professoras relataram que por trabalharem em instituições particulares, as salas de aulas estão cada vez mais cheias, porque a direção das escolas não quer dividir as turmas, pois assim terão mais gastos.

No entanto, os relatos mostram que o acúmulo de crianças na sala de aula acarreta uma desmotivação do aluno também, pois apresentam mais dificuldade em relacionar-se com a professora e colegas, gera certos empecilhos para poderem questionar suas dúvidas e as professoras reclamam das conversas paralelas que atrapalham o rendimento. Como ilustrou uma entrevistada: " $E$ tanta criança na sala, que a gente nem consegue dar atenção pra todos”.

O motivo citado pelas professoras com relação à falta de motivação dos alunos em sala de aula, gera uma incerteza, pois de um lado encontramos os alunos, com preferências em outros assuntos que não estão relacionados aos estudos, e do outro, as professoras cansadas. Frente a esse fato, Pozo (2002) explica que "a motivação não depende só dos motivos que temos, mas do sucesso que esperamos se tentamos alcançá-los” (p. 142). Todas as entrevistadas disseram que precisam de uma certa motivação para ensinar seus alunos. E ao relatar os tipos de motivação que as fazem ficar entusiasmadas, a grande maioria citou a expectativa e receptividade dos alunos. "O que mais me frusta, é quando criamos uma grande expectativa em torno da nossa aula. E o retorno que os alunos dão não estava de acordo com o que a gente imaginou. Isso nos deixa totalmente desmotivadas".

Relataram que para motivarem seus alunos em sala de aula para os estudos, elas trazem diferentes atrativos. "Faço muito jogo para chamar a atenção deles. Quando os aparelhos da escola estão funcionando, eu sempre ocupo". As professoras entrevistadas preocupam-se em realizar aulas diferentes, pois acreditam que a motivação pelo estudo deve ser dada por elas. No entanto, Pozo (2002) acredita que o aluno deve criar uma certa expectativa com relação à aprendizagem, para assim sentir-se motivado. Com relação ao assunto em 
KNÜPPE, L. Motivação e desmotivação: desafio para as professoras...

discussão, Huertas (2001) explica que passamos por fases motivacionais, as quais estão relacionadas com os desejos. Ou seja, segundo o autor, a motivação enfatiza nossos desejos, nossas expectativas e nossas metas. Portanto, pode-se interpretar que nem sempre o que deseja o professor está relacionado ao desejo do aluno.

Ao serem questionadas sobre as metas de ensino, as professoras enfatizaram que gostariam que seus alunos aprendessem. Apenas uma das entrevistadas disse que possui como meta de ensino transmitir aos alunos prazer pelos estudos. "Minha meta de ensino é transmitir aos meus alunos prazer pelos estudos, pois eles precisam estudar pra serem alguém nesta vida. E estudar precisa ser uma coisa boa pra eles".

As professoras acreditam que a motivação pelos estudos, como já mencionado anteriormente, é em grande parte, passado por elas em sala de aula, pois se preocupam com o interesse de seus alunos. Comentaram que sempre que possível, trazem recursos para dentro da sala de aula. "Procuro trazer um filme. Criança pequena gosta dessas coisas”. Quanto a isso, Pozo (2002) salienta que "a possibilidade que um professor tem de mover seus alunos para a aprendizagem depende em grande parte de como ele mesmo enfrenta sua tarefa de ensinar” (p. 145). Para essas professoras, a profissão está em primeiro lugar, ou seja, alegaram que gostam do que fazem, e mesmo com tantos pontos negativos como a falta de reconhecimento profissional e a má remuneração, não atingem seus objetivos, que são o de ensinar. Acreditam que o que as motiva na profissão é a retribuição de seus alunos, seja com um sorriso, um abraço ou uma cartinha dizendo: "Profe, eu te amo".

Durante as entrevistas, foi possível perceber que as professoras estão motivadas com sua profissão, não pelo salário oferecido, mas pelo retorno que têm de seus alunos. Como comentou uma entrevistada: "Só quem é professora sabe disso. As crianças chegam sabendo escrever o nome. E no final do ano, escrevem e lêem textos. E tu sabes que quem fez aquilo foste tu. Isso não tem explicação. É maravilhoso. É muito gratificante". O encanto das educadoras com o resultado obtido pelos alunos ao final do ano, destacou-se nas entrevistas como sendo a maior motivação delas para com a profissão. Segundo Pozo (2002), “ninguém levará os outros a aprender se não houver nele também um movimento para a aprendizagem” (p. 145).

Foi possível constatar a partir das entrevistas, que as professoras apresentam motivações diferentes, ou seja, o que motiva uma a dar aula, não é o mesmo que a outra. Como relatou uma professora: "Sabe, eu gosto quando meus alunos me perguntam bastante; isso me motiva. Já para minha paralela, ela acha que isso não a motiva muito, pra ela motivação é quando os 
alunos trazem bastante material de casa pra contribuir com os estudos em aula”. Frente a esses comentários, Zenti (2000) explica que a motivação não é apenas algo natural, mas depende de fatores externos, por isso, as pessoas apresentam motivações diferentes para o mesmo assunto. Para Huertas (2001), os motivos que levam as professoras a construírem suas aulas estão baseados nos incentivos emocionais. Portanto, pessoas diferentes possuem metas e objetivos diferentes, bem como incentivos diferentes, o que as levam possuir motivações diferentes.

Outro ponto destacado nas entrevistas é com relação aos castigos que os pais dão aos filhos caso não consigam atingir a média. "A gente vê cada coisa. Criança com sete ou oito anos, se não tiram dez, os pais deixam de castigo". As professoras comentaram que não acreditam que o castigo seja a maneira mais correta de motivar uma criança para o estudo. Destacam que a troca, ou seja, a sanção por reciprocidade, pode ser uma grande aliada nesse processo. Pozo (2004), explica que o castigo ou a atribuição de prêmios está relacionado com o que os pais pensam se tratar de motivações comuns na aprendizagem. Ou seja, atribuem castigo ou prêmios em troca de um retorno. Segundo o autor, "trata-se de conseguir algo desejado ou de evitar algo indesejado, em troca de aprender" (p. 139). Neste caso, interpreta-se que muitas vezes os pais possuem um desejo que não é o mesmo de seu filho. Quando o desejo é aprender, a criança o fará sem que ocorram punições ou castigos. Tapia (1999) salienta que muitas vezes o castigo poderá acarretar efeitos contrários aos desejados.

As professoras relataram que um dos grandes motivos da falta de interesse pelos estudos, muitas vezes está relacionado às notas baixas. As crianças, de acordo com o relato das professoras, ficam em suas casas sozinhas ou na companhia da avó ou da empregada, que na maioria das vezes não estão engajadas com a escola e as tarefas escolares. Essa situação motiva as crianças a não estudarem em suas casas, mas a ficarem brincando, pois na grande maioria das vezes não há uma cobrança por parte destas pessoas para com os estudos, o que causa um baixo rendimento nas provas, gerando notas baixas. Assim, acreditam que precisam motivar seus alunos para os estudos, em sala de aula. Fita (1999) salienta em seus estudos que o baixo rendimento pode estar associado à má interpretação das informações, ou seja, os alunos não aprender a pensar. De acordo com Huertas (2001), a motivação pode ser o caminho para um melhor rendimento escolar.

A desmotivação pelos estudos foi apontado como sendo o grande problema das escolas. Muitas crianças chegam cansadas nas escolas porque tiveram uma manhã cheia de atividades (judô, natação, futebol, aula de dança, aula de inglês). Outras preferem brincar com jogos eletrônicos e não fazem as tarefas escolares, e, segundo as entrevistadas, chegam na escola preocupados com a 
KNÜPPE, L. Motivação e desmotivação: desafio para as professoras...

hora da saída para continuarem sua brincadeira em casa, além da falta de cobrança de muitas famílias, que muitas vezes por causa do acúmulo de tarefas e o excesso de trabalho, atribuem pouco tempo aos seus filhos. As professoras acreditam que o incentivo dos pais é muito importante para a formação das crianças, como relatou uma entrevistada: "Que incentivo a criança vai ter? Ela chega em casa e a mãe não pede nem pra ver o caderno. Não pergunta nem como foi a aula". As entrevistadas apontaram que o incentivo da família auxilia na motivação das crianças para com os estudos.

Ao serem indagadas sobre como motivam seus alunos em sala de aula, as professoras foram unânimes, afirmando que dão o melhor de si, procuram trazer atrativos que os motivam, assuntos e trabalhos interessantes, para que assim, consigam estimular as crianças para os estudos. "Acredito que é de pequeno que se aprende a estudar. Por isso faço de tudo pra eles gostarem de vir para a escola". Mas acreditam que seus alunos aprendem melhor aquilo que é de interesse deles. Alguns alunos da quarta série do ensino fundamental, segundo as professoras, alegam que aprendem coisas que não gostam, ou seja, de acordo com a interpretação das entrevistadas, "aprendem coisas que não fazem sentido a eles”. Segundo os estudos de Tapia (1999), é importante as crianças aprenderem algo que faça sentido, como por exemplo, "descobrir, por trás das palavras que se constroem, significados conhecidos e experimentar o domínio de uma nova habilidade, encontrar explicação para um problema relativo a um tema que se deseja compreender" (p. 19).

A importância do planejamento das aulas foi um ponto destacado pelas entrevistadas. Como ressaltou uma professora: "Eu me preocupo muito com a aula que vou dar. Eles são pequenos, mas cheio de energia. Por isso, procuro planejar aulas criativas e envolventes. Porque as crianças precisam gostar de ir à escola". Quanto a isso, Fita (1999) explica que "decidir que tarefas, que atividades de ensino-aprendizagem os alunos realizarão é uma das tarefas mais criativas que nós, professores, realizamos" (p. 111), o que vem a confirmar o depoimento da entrevistada.

A discussão acerca deste estudo mostra que para haver aprendizagem é necessário haver motivação. Para que o aluno esteja envolvido com os estudos, isto deve fazer sentido a suas expectativas, ou seja, deve fazer parte de suas metas. $\mathrm{O}$ mesmo pode-se falar das professoras, as quais precisam estar motivadas com a profissão, para cumprirem com êxito seus objetivos.

As situações discutidas neste estudo revelam que a motivação é a base do estudo. Ou seja, é preciso estar motivado com o assunto, para que ocorra aprendizagem. No entanto, como constatado nesta pesquisa, a motivação varia de pessoa para pessoa, uma vez que está ligada aos interesses e metas 
KNÜPPE, L. Motivação e desmotivação: desafio para as professoras...

a serem atingidas.

\section{Conclusão}

A questão da motivação para os estudos é um assunto que continua em discussão, pois de acordo com os depoimentos e das constatações deste estudo, as crianças chegam cada vez mais desinteressadas pela escola. No entanto, os achados mostram que "a motivação pode ser considerada como um requisito, uma condição prévia da aprendizagem. Sem motivação não há aprendizagem” (POzo, 2002, p. 146). De acordo com as entrevistadas, o que desmotiva as crianças para com os estudos são as encantadoras tecnologias como, por exemplo, o vídeo-game e jogos eletrônicos, que não estão disponíveis na escola, além da falta de cobrança de muitos pais em casa.

As professoras relataram que estão preocupadas com essa desmoti-vação infantil, e frente a isso, buscam alternativas através de aulas diferenciadas e recursos tecnológicos. Percebe-se que, mesmo enfrentando problemas com a baixa remuneração e o não reconhecimento da profissão, as professoras esforçam-se em motivar seus alunos em sala de aula. As entrevistadas acreditam que para seus alunos obterem um bom resultado escolar ao final do ano letivo e para se engajarem com os estudos, é preciso que estejam motivados com os mesmos. Essa motivação deve partir do aluno, mas o professor e a escola precisam oferecer subsídios para que isso aconteça. Pode-se ser citado como subsídio em primeiro lugar a aproximação dos conteúdos escolares com a realidade das crianças, pois muitas vezes são discutidos assuntos em sala de aula, que o aluno desconhece. Por essa razão, a pesquisa constatou que explicar por que e como utilizar certos conteúdos escolares pode auxiliar na motivação dos alunos.

Outro fato mencionado é a concorrência que as escolas possuem com a mídia, pois segundo as entrevistadas, para uma criança são muito mais envolventes os brinquedos do que os estudos. Quanto a essa afirmação, percebe-se que as professoras precisam motivar ainda mais seus alunos. A desmotivação foi um dos pontos citados nos resultados da pesquisa como sendo o principal motivo pela falta de interesse pelos estudos. No entanto, os resultados mostraram que essa desmotivação é causada por diversos fatores. Um deles, como já mencionado na análise, é a vida do mundo moderno, ou seja, pais saem para trabalhar e necessitam deixar seus filhos com avós ou empregadas, as quais 
KNÜPPE, L. Motivação e desmotivação: desafio para as professoras...

não cobram os estudos e a execução de tarefas em casa. Ocorre em muitos casos, a execução das tarefas pelas próprias pessoas adultas, e a criança de nada participa. Esse apontamento é um problema ocorrido na grande maioria das escolas que participaram da pesquisa. A concorrência com os brinquedos eletrônicos também apareceu como sendo uma das causas do desinteresse. As crianças atribuem grande parte de seu tempo para esses atrativos tecnológicos e acabam esquecendo das tarefas escolares.

A discussão dos resultados obtidos na pesquisa mostrou que a família possui um papel muito importante na motivação das crianças pelos estudos. Foi apontado como necessário o incentivo da família, como, por exemplo, perguntar ao filho como foi a aula ou pedir para ver o caderno. Esses fatores auxiliam na motivação, uma vez que a criança vai à escola com o prazer de voltar para casa e poder comentar como foi seu dia. A pesquisa mostrou que esse tipo de atitude por parte da família é muito importante para uma criança que freqüenta uma escola de Ensino Fundamental ( $1^{\mathrm{a}}$ a $4^{\mathrm{a}}$ série).

No entanto, a análise mostrou que as professoras estão preocupadas com esses fatos mencionados, e começaram a modificar suas aulas. A cópia do quadro passou a diminuir, e a confecção de jogos e pesquisas dentro da escola começou a fazer parte do dia a dia escolar. As entrevistadas relataram que utilizam diferentes recursos em suas aulas como jogos no computador, pesquisa na internet e confecção de materiais pelos próprios alunos, garantindo assim uma maior atenção e interesse dos mesmos.

Segundo Tapia (1999), algo que pode auxiliar os professores a compreender a motivação de seus alunos é observar seus comportamentos, o que dizem e o que fazem as crianças quando precisam realizar atividades relacionadas com a aprendizagem. Outro fato importante relatado pelo autor é que os professores podem conquistar a motivação de seus alunos mostrando, no início da aula, curiosidades relacionadas ao tema, e relatar a importância do conteúdo. Mesmo sendo crianças de $1^{\mathrm{a}}$ a $4^{\mathrm{a}}$ série, isso pode ser abordado, e com certeza fará com que os alunos tenham mais interesse pelos estudos.

Em suma, o presente estudo mostrou que as professoras do Ensino Fundamental $\left(1^{\mathrm{a}}\right.$ a $4^{\mathrm{a}}$ série) precisam motivar seus alunos para o ensino, e para isso necessitam estar motivadas, realizar atividades criativas e envolventes. É importante que questionem seu trabalho, com o intuito de analisar os benefícios que o mesmo oferece aos alunos. Evidentemente, sabe-se da importância da motivação em sala de aula, porém a reflexão sobre o assunto é imprescindível.

Foi possível constatar que "não existem receitas mágicas que melhorem a motivação de nossos alunos” (FITA, 1999, p. 127). Nossa profissão exige que 
o professor seja criativo e dinâmico, mas para isso precisa-se estar motivado e com metas e objetivos bem esclarecidos.

\section{REFERÊNCIAS}

ANDRÉ, M. E. D. A. de. Etnografia da prática escolar. 2. ed. Campinas: Papirus, 1998.

BARDIN, L. Análise de conteúdo. Lisboa: Edições 70, 1991.

BOGDAN, R.; BIKLEN, S. Investigação qualitativa em educação: uma introdução à teoria e aos métodos. Porto: Porto Editora, 1994.

CHIZZOTTI, A. Pesquisa em ciências humanas e sociais. São Paulo: Cortez, 1991.

FITA, E. C. O professor e a motivação dos alunos. In: TAPIA, J. A.; FITA, E. C. A motivação em sala de aula: o que é, como se faz. 4. ed. São Paulo: Loyola, 1999. p. 65-135.

HUERTAS, J. A. Motivación: querer aprender. Buenos Aires: Aique, 2001.

JESUS, S. N. de; SANTOS, J. C. V. Desenvolvimento profissional e motivação dos professores. Educação: Revista da Faculdade de Educação, Porto Alegre: PUCRS, v. 27, n. 52, p. 39-58, 2004.

MORAES, R. Análise de conteúdo. Educação: Revista da Faculdade de Educação, Porto Alegre: PUCRS, v. 22, n. 37, p. 7-31, 1999.

MOREIRA, H. A investigação da motivação do professor: a dimensão esquecida. Educação \& Tecnologia, Curitiba, v. 1, p. 88-96, 1997.

POZO, J. I. Aprendizes e mestres: a nova cultura da aprendizagem. Porto Alegre: Artmed, 2002.

TAPIA, J. A. Contexto, motivação e aprendizagem. In: TAPIA, J. A.; FITA, E. C. A motivação em sala de aula: o que é, como se faz. 4. ed. São Paulo: Loyola, 1999. p. 11-61.

TORRE, J. C. Apresentação: a motivação para a aprendizagem. In: TAPIA, J. A.; FITA, E. C. A motivação em sala de aula: o que é, como se faz. 4. ed. São Paulo: Loyola, 1999. p. 7-10.

ZENTI, L. Aulas que seus alunos vão lembrar por muito tempo: motivação é a chave para ensinar a importância do estudo na vida de cada um de nós. Nova Escola, São Paulo: Abril, v. 134, ago. 2000. 
KNÜPPE, L. Motivação e desmotivação: desafio para as professoras...

Texto recebido em 11 abr. 2005

Texto aprovado em 28 out. 2005 